\title{
Kısa Vadeli Borçlanmanın İşletmelerin Aktif Karlıııları Üzerine Etkisi: BİST Çimento Sektörü Üzerine Bir Uygulama
}

\author{
Murat KAYA* \\ Hakan TUNÇ** \\ Fatih TOPÇUOĞLU***
}

\section{ÖZET}

İşletmelerin karlılıklarını etkileyen farklı değişkenler olmakla birlikte, varlık finansmanı için tercih ettikleri finansman politikaları bu değişkenler arasında önemli yer tutmaktadır. Finansman politikalarının tercihi, işletmelerin risk seviyelerini ve karlılıklarını etkilemekte olup, söz konusu etki işletmelerin faaliyette bulundukları sektör ile de yakından ilgilidir. Çalışmada BiST'te işlem gören 10 çimento şirketinin 1998-2016 tarihleri arasina ilişkin 3'er ayllk verileri kullanılarak kısa vadeli borçlanma oranları, stok tutma süreleri ve alacak tahsil süreleri ile aktif karlılıkları arasındaki ilişki analiz edilmiştir. Analiz için lojistik regresyon modeli kullanılmış olup analiz sonucunda, çimento sektöründe faaliyette bulunan işletmelerin kısa vadeli borçlanmaya ağırlık vererek uyguladıkları finansman politikaları ve stok tutma sürelerinin artmasının aktif karlılıklarını olumsuz etkilediği sonucuna ulaşılmuştır. sektörü.

Anahtar Kelimeler: Kaldıraç, kısa vadeli borçlanma, aktif karlılığı, logistik regresyon, çimento

JEL Siniflandirmast: G31, G32.

\begin{abstract}
Effect Of Short-Term Borrowings On Return On Assets Of Companies: An Application On The BIST Cement Sector

\section{ABSTRACT}

With different variables affecting the profitability of businesses, preferred financing policies for asset financing it has an important place among these variables. While preference for financing policies, affects the risk levels and profitability of entities, they are also closely related to the sector in which they operate. In this study the relationship between short term debt ratios, inventory conversion periods, receivables collection periods and asset profitability was analyzed by using 3-month data of cement companies that were traded in BIST during 1998-2016 period. The logistic regression model was used for the analysis. As a result of the analysis, the financing policies applied by the companies operating in the cement sector, focusing on short-term debt, and the increase in stock holding times have affected the asset profitability negatively.
\end{abstract}

Keywords: Leverage, short-term borrowing, return on assets, logistic regresyon, cement sector. Jel Classification: G31, G32.

\footnotetext{
*Yrd. Doç. Dr. Murat Kaya, Mehmet Akif Ersoy Üniversitesi, İktisadi ve İdari Bilimler Fakültesi, mkaya@mehmetakif.edu.tr.

** Yrd. Doç. Dr. Hakan Tunç, Mehmet Akif Ersoy Üniversitesi, İktisadi ve İdari Bilimler Fakültesi, htunc@mehmetakif.edu.tr.

*** Arş. Gör. Fatih Topçuoğlu, Mehmet Akif Ersoy Üniversitesi, Zeliha Tolunay Uygulamalı Teknoloji ve İşletmecilik Yüksekokulu, ftopcuoglu@mehmetakif.edu.tr
} 


\section{GíRiş̧}

Günümüzün artan rekabet koşulları ve riskleri, işletmelerin sahip oldukları varlıkların etkin kullanımını zorunlu hale getirmiş bu bağlamda işletmelerin sahip oldukları varlıkların yönetilmesi önem kazanmıştır. İşletmeler faaliyetlerini sürdürürken farklı amaçlarla varlık yatırımları gerçekleştirmekte olup, varlıklar temel olarak dönen varlık ve duran varlık sınıflandırması ile ifade edilmektedir. Söz konusu varlıkların dağılımı sektörel bazda farklılık göstermekle birlikte, ticari işletmelerin dönen varlık ağırlıklı, üretim işletmelerinin ise duran varlık ağırlıklı faaliyet sürdürmeleri beklenmektedir. Söz konusu varlıklara ilişkin yatırımlar, işletmeler açısından doğru analiz edilmesi ve karar verilmesi gereken süreçlerdir. İşletmelerin yatırım süreçleri sadece yatırım yapılacak varlıkların belirlenmesi ile sınırlı olmayıp, yatırımların finansmanı konusunu da içermektedir. Doğru varlıkların yanlış kaynaklardan finansmanı, işletmelerin verimliliklerini ve dolayısıyla karlılıklarını olumsuz etkileyebilmektedir. Klasik finans görüşü olarak, vade uyumu nedeni ile, dönen varlıkların kısa vadeli borçlanma yolu ile, duran varlıkların ise uzun vadeli borçlanma yolu ile finanse edilmeleri kabul görmektedir. Fakat bu finansman politikası işletmelerin faaliyette bulunduğu sektör, karlılık beklentileri ve riskleri göz önünde bulundurulduğunda değişkenlik gösterebilmektedir. Ayrıca faaliyette bulunan ekonominin yapısal koşulları gereği uzun vadeli borçlanma imkanlarının sınırlı olması, işletmelerin kısa vadeli borçlarının dolayısıyla risklerinin artmasına neden olmaktadır. İşletme yöneticileri kaldıraç etkisinden yararlanmak amaciyla borçlanma yoluna gittiklerinde ise risklerini arttırmakta ve bu durumda karlılık üzerinde olumsuz etkiye sebep olabilmektedir. Bu nedenle günümüzde varlıkların finansman kaynakları, karlılık üzerindeki etkisinden dolayı işletme finansının önemli bir alanını oluşturmaktadır.

\section{BORÇLANMA KARLILIK İLIŞKİSI}

İşletmelerin varlık finansmanı için kullanabilecekleri temel de iki kaynak bulunmaktadır. Söz konusu kaynaklar; borç olarak ta ifade edilen yabancı kaynak ve işletmelerin kendilerine ait kaynakları olan özkaynaklardır. Her iki kaynağın da finansman maliyetleri olup, işletmelerin sermaye yapıları sonucunda ağırlıklı ortalama sermaye maliyeti ortaya çıkmaktadır. Varlıklarının finansmanını özkaynakları ile sağlayan işletmeler açısından özkaynak maliyeti; işletmelerin hisse senetlerini satın alarak özkaynak sağlayan yatırımcıların söz konusu yatırımdan beklemiş oldukları getiriden oluşmaktadır (Aydın, vd., 2014: 244). Borçlanma maliyeti ise, borçlanma yoluyla sağlanan nakit girişleri ile vade sonunda borçlanma karşıllğı ödenecek olan faiz ve anapara için gerekli nakit çıkışlarını eşitleyen iskonto oranı ile ifade edilmektedir(Okka, 2011: 195). İşletmelerin varlık finansmanı noktasında, özkaynak ve borçlanma alternatiflerini birlikte kullanması durumunda ağırlıklı ortalama sermaye maliyeti ortaya çıkmakta olup; alternatif fon kaynaklarının vergi sonras1 maliyetleri ile sermaye yapısı içindeki oranlarının çarpımlarının toplamı ile elde edilmektedir (Ceylan ve Korkmaz, 2013: 234). Bu bağlamda işletmelerin varlık finansmanı için tercih edecekleri sermaye bileşenleri, işletmelerin piyasa değerleri ve karlılıkları üzerinde etkili olabilmektedir.

Varlık finansmanı için kullanılan borçların kar veya zarar üzerindeki etkisi finansal kaldıraç olarak ifade edilmekte olup, işletmelerin toplam varlıkları üzerinden karlılığ borçlanma maliyetinden yüksekse finansal kaldıracın olumlu, düşük ise olumsuz etkisinden söz edilebilir. İşletmelerin ihtiyaç duydukları kaynakları borçlanma yoluyla sağlamak 
istemelerindeki temel sebep, borçlanma maliyetinin özkaynak maliyetinden düşük olmasıdır(Ceylan ve Korkmaz, 2013: 55). Bu sayede işletmeler kaldıraç etkisinden yararlanarak karlılıklarını arttırmak istemektedirler. Fakat işletmeler açısından yabancı kaynak veya özkaynak kullanımı, faaliyette bulunulan ülkenin finansal yapısı ve ekonomik durumundan bağımsız değildir. Borçlanma imkanlarının kısıtlı olduğu ülkelerde işletmeler daha çok özkaynak ağırlıklı finansman gerçekleştirmek zorunda kalırken, finansal piyasaları gelişmiş, finansal araç sayısı fazla olan ülkelerde işletmeler borçlanma imkanları sayesinde kaldıraç etkisinden daha çok faydalanabilmektedir(Akkaya, 2008: 3).

İşletmelerin kaynak yapısı içerisinde borçlanmaya ağırlık vermesi işletme risklerinin artmasına neden olmaktadır. Bu nedenle borçlanmanın işletmelere sağlayacağı avantajlardan yararlanmak için, kaynak yapısı işletmenin faaliyette bulunduğu sektöre uygun olarak optimal düzeyde borç özkaynak dengesi sağlanacak şekilde oluşturulmalıdır(Çabuk ve Lazol, 2013: 208).

İşletmelerin varlık finansmanında, borçlanmadan yararlanma kapasitesinin göstergesi olarak finansal oranlar kullanılmakta olup, söz konusu oranlar mali yapı veya kaldıraç oranları ile ifade edilmekte ve bu oranlar kullanılarak borçlanmanın işletmelerin karlılıklarına olumlu veya olumsuz etkisi ile aktiflerin finansmanında kullanılan borç ve özkaynak bileşenleri hakkında bilgi sahibi olunmaktadır(Bektöre vd., 2015: 159). Bu çalışmada, kısa vadeli borçlanma oranı, stok tutma süresi ve alacakların tahsil süresinin karlılık göstergelerinden olan aktif karlılığ

\section{ARAŞTIRMANIN LITERATÜRÜ}

Konu ile alakalı dünyada ve Türkiye'de birçok çalışma mevcuttur. Yapılan çalışmalardan bir kısmı, elde edilen sonuçlar itibariyle aşağıda ifade edilmiştir.

Topal (2006), BİST'e kayıtlı imalat işletmelerinin 1997-2003 tarihi arası verilerini kullanarak finansal kaldıraç oranlarının karlılık üzerine etkisini incelediği çalışmasında, varlıkların borçla finanse edilmesinin belirli bir seviyeye kadar karlılığı olumlu etkilediği, belirli bir seviyeden sonra ise karlılığa olumsuz etkiye sebep olduğu sonucuna ulaşmıştır.

Raheman ve Nasr (2007), Karachi Borsası'nda işlem gören 94 firmanın 1999-2004 yılları arası verilerini kullanarak, ortalama alacak tahsil süresi, ortalama borç ödeme süresi, nakit dönüşüm süresi ve cari oran gibi işletme sermayesi değişkenlerinin, net işletme karı üzerindeki etkisini inceledikleri çalışmalarında, nakit dönüşüm süresi, likidite ve borçlanma ile karlılık arasında negatif yönlü, işletme büyüklüğü ile karlılık arasında ise pozitif yönlü ilişki olduğu sonucuna ulaşmışlardır.

Albayrak ve Akbulut, (2008), BİST sanayi ve hizmet sektöründe işlem gören firmaların karlılıklarını etkileyen finansal değişkenleri araştırdıkları çalışmalarında, sermaye yapısına ilişkin finansal oranların, aktif karlılığını en çok etkileyen değişkenler olduğu ve söz konusu oranların aktif karlılığını negatif etkilediği sonucuna ulaşmışlardır.

Salawu (2009), Nijerya Borsası'nda işlem gören 50 şirketin sermaye yapısı ile karlılıkları arasındaki ilişkiyi 1990-2004 yılları arasına ilişkin verileri kullanarak incelediği çalışmasında, karlılığın kısa vadeli borçlanma ile pozitif, uzun vadeli borçlanma ile negatif 
yönlü ilişkisinin olduğu, ayrıca borçlanma oranı ile karlılık arasında negatif yönlü ilişki olduğu sonucuna ulaşmıştır.

Mohamad ve Saad (2010), Malezya'da işlem gören şirketlerin işletme sermayesi yönetiminin, firma performansı ve karlılık ilişkisini inceledikleri çalışmalarında, nakit dönüşüm süresi, cari oran, cari varlıkların toplam varlıklara oranı, kısa vadeli yükümlülüklerin toplam varlıklara oranı, borçların aktiflere oranı ile ifade ettikleri işletme sermayesi değişkenlerinin, Tobin Q, aktif karlılığı ve yatırım sermaye getirisi ile ifade ettikleri firma performansına etkileri analiz edilmiş ve işletme sermayesi değişkenleri ile firma performansı arasında negatif yönlü ilişki olduğu sonucuna ulaşmışlardır.

Zubairi (2010), Karachi Borsası otomotiv sektöründe işlem gören 30 şirket üzerinde yapmış olduğu çalışmasında, finansal kaldıracın işlemelerin karlılığını olumlu yönde etkilediği sonucuna ulaşmıştır.

Karadeniz ve İskenderoğlu, (2011), BİST’te işlem gören turizm şirketlerinin aktif karlılığını etkileyen değişkenleri analiz ettikleri çalışmalarında, kaldıraç oranının aktif karlılığı üzerinde negatif etkiye sahip olduğu sonucuna ulaşmışlardır.

İskenderoğlu, Karadeniz ve Atioğlu (2012), BİST’e kote olan 13 bankanın, büyüklük, büyüme ve sermaye yapısı kararlarının karlılık üzerine etkisini inceledikleri çalışmalarında, sermaye yapısına ilişkin oranların bankaların karlılıkları üzerinde negatif yönlü etkiye sahip olduğu sonucuna ulaşmışlardır.

Doğan (2013), BİST’te işlem gören sigorta şirketlerinin sermaye yapılarının aktif karlılıkları üzerine etkisini incelediği çalışmasında, sigorta şirketlerinin hasar prim oranı, kaldıraç oranı ve likit aktiflerindeki artışın karlılığı olumsuz, aktif büyüklüğündeki artışın ise karlılığı olumlu etkilediği sonucuna ulaşmıştır.

Makori ve Jagongo (2013), Kenya'da işlem gören şirketlerin işletme sermayesi yönetimi ve karlılıkları arasındaki ilişkiyi inceledikleri çalışmalarında, alacak tahsil süresi ve nakit dönüşüm süresi ile karlılık arasında negatif yönlü bir ilişki olduğu ayrıca, finansal kaldıraç, satışlardaki büyüme, cari oran ve firma büyüklüğünün karlılık üzerinde etkili olduğu sonucuna ulaşmışlardır.

Chechet ve Olayiwola, (2014), Nijerya Borsası'nda işlem gören 70 şirketin 2000-2009 yılları arası verilerini kullanarak yapmış oldukları çalışmalarında, borçlanma oranının işletmelerin karlılıklarını negatif yönde etkilediği sonucuna ulaşmışlardır.

Hussain (2015), 2007-2013 yılları arası verilerini kullanarak yapmış olduğu çalışmasında, borçlanma oranında yıllar itibari ile meydana gelen artışın işletmelerin karlılığını azalttığı sonucuna ulaşmıştır.

Karadeniz, Kaplan ve Günay, (2016), BİST’te işlem gören 8 turizm şirketinin 20092015 yılları arası verilerini kullanarak, sermaye yapısı kararlarının karlılık üzerine etkisini inceledikleri çalışmalarında, kısa vadeli kaldıraç ile toplam kaldıracın işletmelerin net kar marjı, aktif kazanç gücü ve aktif karlılığı üzerinde olumsuz etkisi olduğu sonucuna ulaşmışlardır. 


\section{KISA VADELİ BORÇLANMANIN FİRMALARIN AKTIFF KARLILIĞINA ETKİSINNE YÖNELIKK BİR UYGULAMA}

Çalışmanın bu bölümünde, kısa vadeli borçlanmanın firma aktif karlılığı üzerine etkisini analiz etmek için lojistik regresyon modeli kullanılarak BİST üzerinde istatistiksel bir uygulama yapılmıştır. Bağımlı değişkenin nominal ölçekli olduğu modellerde bağımsız değişkenin etkisini analiz edebilmek için lojistik regresyon modelleri kullanılabilmektedir(Kalayc1, 2005: 273). Ayrıca lojistik regresyon modelinde doğrusal regresyon modellerinden farklı olarak katsayı tahmini yaparken en küçük kareler yöntemi kullanılmadığı için normal dağılım ve değişmeyen varyans varsayımları bulunmamaktadır. Lojistik regresyon modeli katsayı tahmininde maksimum olabilirlik tekniğini kullanmaktadır(Kalaycı, 2005: 273). Bu teknik bir olayın gerçekleşme ihtimalinin, o olayın gerçekleşme olasılığının en yüksek olmasından kaynaklandığı ilkesine sahiptir.

Uygulamada, bağımlı değişken olarak aktif karlılık oranı kullanılmıştır. Aktif karlılığı, işletmelerin gerçekleştirdikleri faaliyetlerde, aktifleri ne kadar verimli kullandıklarının ve aktiflerin meydana getirdiği katma değerin bir göstergesidir. Aktif karlılığının ağırlıklı ortalama sermaye maliyetinden yüksek olması hedeflenmektedir(Toroslu ve Durmuş, 2015: 168). Aktif karlılığı aşağıdaki gibi hesaplanmaktadır.

\section{Aktif Karlılığ $1=$ Net Kar / Toplam Aktif}

Çalışmada bağımsız değişkenler olarak, kısa vadeli borçlanma oranı, stok tutma süresi ve alacakların tahsil süresi kullanılmıştır. Çalışmanın temel amacı, kısa vadeli borçlanmanın aktif karlılığ 1 üzerindeki etkisinin ölçülmesi olmakla birlikte, kurulan modelin güvenirliliğinin arttırılması amacıyla, aktif karlılığını etkileyen stok tutma süresi ve alacakların tahsil süresi de bağımsız değişkenler olarak analize dahil edilmiştir. İşletmelerin ülkemizde sermaye piyasasını kullanarak uzun vadeli borçlanma imkanlarının kısıtlı olması nedeni ile ağırlıklı olarak kısa vadeli borçlanmalarından dolayı, kısa vadeli borçlanma oranı önem taşımaktadır. Söz konusu oran, işletmelerin kaynak yapısı içerisinde kısa vadeli borçların payını ve aktiflerin ne kadarlık kısmının kısa vadeli kaynaklarla finanse edildiğini göstermektedir. Özellikle sanayi işletmelerinde oranının yüksek çıkması işletme riskinin arttığını ifade etmekle birlikte, oranın işletmelerin faaliyette bulundukları sektör dikkate alınarak değerlendirilmesi gerekmektedir. Ayrıca uzun vadeli borçlanma imkanlarının sınırlı olduğu ekonomilerde oranın yüksek çıkması beklenen bir durumdur(Çabuk ve Lazol, 2013: 211). Çalışmada diğer bağımsız değişkenler arasında yer alan stok tutma süresi; işletmelerin stoklarını ne kadarlık süre içerisinde satabildiklerini göstermekte olup, diğer bağımsız değişken olan alacakların tahsil süresi ise, işletmelerin alacaklarını ne kadarlık süre içerisinde tahsil edebildiklerini göstermektedir. İşletmeler açısından gerek stok tutma süresi gerekse alacakların tahsil süresinin azalması, işletmelerin stoklarını ve alacaklarını finanse etmek için ihtiyaç duydukları kaynakların azalmasına, beraberinde finansman maliyetlerinin düşmesine ve bunun sonucunda karlılığın olumlu etkilenmesine olanak sağlamaktadır(Sakarya, 2008: 235-236). Çalışmada kullanılan bağımsız değişkenlerin hesaplanmasına ilişkin formüller aşağıda sunulmuştur. 


\author{
Kısa Vadeli Borçlanma Oranı = Kısa Vadeli Borçlar / Toplam Aktif \\ Stok Tutma Süresi $=($ Stoklar x 360) $/$ Satışların Maliyeti \\ Alacakların Tahsil Süresi $=($ Ticari Alacaklar x 360) $/$ Net Satışlar
}

Lojistik regresyon modellerinde tahmin yapabilmek için bağımlı değişkenin ikili kodlanması gerekmektedir. Çalışmada karlılık için kullanılan her iki değişkende bir önceki yıla göre pozitif bir artış varsa (1), bir önceki yıla göre negatif artış(azalış) varsa (0) olarak kodlanmıştır. Uygulama Borsa İstanbul'da işlem gören ve çimento sektöründe faaliyet gösteren 10 firma üzerinde yapılmıştır. Araştırmanın çimento sektörü üzerine yapılmış olmasının nedeni, çimento sektörünün inşaat sektörünün katalizör sektörü ve inşaat sektörünün de son yıllarda hızlı büyüyen sektörlerden birisi olmasıdır. Analize konu olan firmalar Adana Çimento, Afyon Çimento, Akçansa Çimento, Bolu Çimento, Bursa Çimento, Çimsa Çimento, Konya Çimento, Mardin Çimento, Nuh Çimento, Göltaş Çimento olup analiz sonuçları aşağıda açıklanmaktadır.

Tablo 1. Omnibus Test Sonuçları

\begin{tabular}{|c|c|c|c|c|}
\hline & Ki-Kare & Step (sig) & Block(sig) & Model(sig) \\
\hline Adana Çimento & 12.131 &, 07 &, 07 &, 07 \\
\hline Afyon Çimento & 20.194 &, 000 &, 00 &, 00 \\
\hline Akçansa Çimento & 28.161 &, 000 &, 00 &, 00 \\
\hline Bolu Çimento & 8,079 &, 044 &, 044 &, 044 \\
\hline Bursa Çimento & 14,713 &, 002 &, 002 &, 002 \\
\hline Çimsa Çimento & 23,754 &, 000 &, 000 &, 000 \\
\hline Konya Çimento & 33,810 &, 000 &, 000 &, 000 \\
\hline Mardin Çimento & 52,257 &, 000 &, 000 &, 000 \\
\hline Nuh Çimento & 1,665 &, 645 &, 645 &, 645 \\
\hline Göltaş Çimento & 15,825 &, 001 &, 001 &, 001 \\
\hline
\end{tabular}

Analizin ilk aşamasında kurulan modellerin bir bütün olarak anlamlılığı test edilmiştir. Bu kısımda, modele sabit terime ek olarak üç yordayıcı değişken eklendiği zaman, modelin bir bütün olarak anlamlılığı ölçülmektedir(Çokluk, 2010: 1385). Tablo 1.'deki sonuçlar incelendiğinde; ki-kare dağılımında Nuh Çimento dışındaki bütün firmalarda olasılık değeri 0.05 'den küçük çıktığı için kurulan modellerin anlamlı olduğu görülmektedir. 
Tablo 2. Model Sonuçları

\begin{tabular}{|l|c|c|c|}
\hline & -2 Log likelihood & $\begin{array}{c}\text { Cox \& Snell } \\
\text { R Square }\end{array}$ & $\begin{array}{c}\text { Nagelkerke } \\
\text { R Square }\end{array}$ \\
\hline Adana Çimento & 77,464 &, 148 &, 213 \\
\hline Afyon Çimento & 84.690 &, 233 &, 312 \\
\hline Akçansa Çimento & 66,635 &, 310 &, 434 \\
\hline Bolu Çimento & 79,529 &, 105 &, 150 \\
\hline Bursa Çimento & 72,890 &, 176 &, 257 \\
\hline Çimsa Çimento & 65,841 &, 268 &, 388 \\
\hline Konya Çimento & 66,223 &, 359 &, 491 \\
\hline Mardin Çimento & 33,218 &, 497 &, 736 \\
\hline Nuh Çimento & 73,037 &, 026 &, 038 \\
\hline Göltaş Çimento & 86,140 &, 188 &, 255 \\
\hline
\end{tabular}

Analizin ikinci aşamasında ise amaçlanan modelin uyum istatistikleri Tablo 2.'de verilmiştir. Modelin çoklu olabilirlik değerleri, ilgili bağımsız değişken modele girdiğinde küçük de olsa bir artış göstermiştir. Ayrıca modelin $\mathrm{R}^{2}$ değerleri de Nuh Çimento dışında sıfirdan uzaklaşan değerlerdir. Lojistik regresyon modelinde Cox \& Snell $\mathrm{R}^{2}$ değeri, bağımlı değişken modele girdiğinde bağımsız değişkendeki varyansı açıklayabilme oranını vermektedir(Çokluk vd., 2012: 93). Tablo 2. incelendiğinde Bolu Çimento ve Nuh Çimento dışında bu oranın \%15'in üstünde olduğu görülmektedir. Analizin üçüncü ve son aşamasında ise katsayı sonuçları incelenecektir.

Tablo 3. Amaçlanan Model Katsayı Tahminleri

\begin{tabular}{|c|c|c|c|c|}
\hline & $\mathbf{B}_{\mathbf{1}}, \mathbf{B}_{2}, \mathbf{B}_{3}$ & $\mathbf{E}(\mathbf{B})_{\mathbf{1}}, \mathbf{E}(\mathbf{B})_{2}, \mathbf{E}(\mathbf{B})_{3}$ & $\mathbf{W a l d}_{1}, \mathbf{W a l d}_{2}, \mathbf{W a l d}_{3}$ & $\mathbf{S i g}_{\mathbf{1}} \mathbf{S i g}_{2}, \mathbf{S i g}_{3}$ \\
\hline Adana & $-11,680$ &, 000 & 6,356 &, 012 \\
Çimento &, 014 & 1,015 & 2,130 &, 144 \\
&,- 049 &, 952 & 5,436 &, 020 \\
\hline Afyon & $-1,223$ &, 294 &, 392 &, 531 \\
Çimento &, 000 & 1,000 &, 010 &, 918 \\
&,- 022 &, 978 & 8,842 &, 003 \\
\hline Akçansa & $-16,741$ &, 000 & 10,300 &, 001 \\
Çimento &, 042 & 1,042 & 4,511 &, 034 \\
&,- 126 &, 881 & 12,440 &, 000 \\
\hline \multirow{2}{*}{ Bolu Çimento } & $-9,284$ & 6,78 & 6,783 &, 009 \\
&, 002 & 0,04 &, 036 &, 850 \\
&, 003 & 0,13 &, 129 &, 720 \\
\hline
\end{tabular}




\begin{tabular}{|c|c|c|c|c|}
\hline $\begin{array}{c}\text { Bursa } \\
\text { Çimento }\end{array}$ & $\begin{array}{c}-7,355 \\
-, 026 \\
-, 054 \\
\end{array}$ & $\begin{array}{l}\text {,001 } \\
, 975 \\
, 947 \\
\end{array}$ & $\begin{array}{l}1,854 \\
2,604 \\
7,587 \\
\end{array}$ & $\begin{array}{l}, 173 \\
, 107 \\
, 006 \\
\end{array}$ \\
\hline $\begin{array}{c}\text { Çimsa } \\
\text { Çimento }\end{array}$ & $\begin{array}{r}-3,917 \\
-, 016 \\
-, 074 \\
\end{array}$ & $\begin{array}{l}, 020 \\
, 984 \\
, 929 \\
\end{array}$ & $\begin{array}{l}-3,92 \\
-0,02 \\
-0,07 \\
\end{array}$ & $\begin{array}{l}, 527 \\
, 539 \\
, 001 \\
\end{array}$ \\
\hline $\begin{array}{c}\text { Konya } \\
\text { Çimento }\end{array}$ & $\begin{array}{r}-8,684 \\
-, 036 \\
-, 026 \\
\end{array}$ & $\begin{array}{l}, 000 \\
, 964 \\
, 975 \\
\end{array}$ & $\begin{array}{c}5,025 \\
2,910 \\
10,633 \\
\end{array}$ & $\begin{array}{r}, 025 \\
, 088 \\
, 001 \\
\end{array}$ \\
\hline $\begin{array}{l}\text { Mardin } \\
\text { Çimento }\end{array}$ & $\begin{array}{r}-31,257 \\
, 026 \\
-, 055 \\
\end{array}$ & $\begin{array}{c}, 000 \\
1,026 \\
, 946 \\
\end{array}$ & $\begin{array}{c}11,592 \\
3,886 \\
5,219 \\
\end{array}$ & $\begin{array}{l}, 001 \\
, 049 \\
, 022 \\
\end{array}$ \\
\hline Nuh Çimento & $\begin{array}{r}-5,862 \\
, 003 \\
, 015 \\
\end{array}$ & $\begin{array}{c}, 003 \\
1,003 \\
1,015 \\
\end{array}$ & $\begin{array}{r}, 525 \\
, 030 \\
, 508 \\
\end{array}$ & $\begin{array}{l}469 \\
, 863 \\
, 476 \\
\end{array}$ \\
\hline $\begin{array}{c}\text { Göltaş } \\
\text { Çimento }\end{array}$ & $\begin{array}{l}-, 692 \\
, 012 \\
-, 057 \\
\end{array}$ & $\begin{array}{c}, 501 \\
1,012 \\
, 944 \\
\end{array}$ & $\begin{array}{c}, 018 \\
1,098 \\
11,081 \\
\end{array}$ & $\begin{array}{l}\text { 894 } \\
\text { 295 } \\
, 001\end{array}$ \\
\hline
\end{tabular}

$\mathrm{P}>, 05, \mathrm{p}>, 10$

10 çimento firması için tahmin edilen katsayılar Tablo 3.'de verilmiştir. Tabloda her çimento şirketi için aynı modelde 3 farklı bağımsız değişken olduğu için üç farklı katsayı tahmini yapılmıştır. Katsayıların raporlanmasında bağımsız değişkenler, kısa vadeli borçlanma oranı (1), alacakların tahsil süresi (2), stok tutma süresi (3) sırası ile verilmiştir.

Katsayıların istatistiksel olarak anlamlılıkları incelendiğinde, 10 farklı çimento firmasının 5'inde, kısa vadeli borçlanma oranın aktif karlılı̆̆ına etkisi $\% 90$ veya $\% 95$ güven aralığında istatistiksel olarak anlamlı çıkmış olup, ilgili modelin katsayıları negatiftir. $\mathrm{Bu}$ ilişki firmaların kısa vadeli borçlanma oranlarındaki artışın, firmaların aktif karlılıklarında azalış yönlü bir etkiye neden olduğunu göstermektedir(İslamoğlu ve Alnıaçık, 2014: 391). Fakat $\operatorname{Exp}(B)$ değerlerinin küçük çıkması $(, 00)$ bu etki gücünün zayıf olduğunu ifade etmektedir.

Ayrıca 10 farklı çimento firması için alacakların tahsil süresi incelendiğinde; sadece üç firmada istatistiksel olarak anlamlı bir etkiye sahip olduğu fakat stok tutma süresinin \%95 güven aralığında 8 firmada istatistiksel olarak anlamlı ve negatif yönlü bir etkiye sahip olduğu tahmin edilmiştir. Stok tutma süresinin negatif yönlü etkiye sahip olması; stokların daha kısa sürede satılmasının satış hacmini arttırması ve bu durumun sonucu olarak stok finansmanı için ihtiyaç duyulan kaynak ve buna bağlı finansman maliyetlerinin azalması sayesinde karlılığın artı̧̧ göstermesi ile açıklanabilir(Sakarya, 2008: 236). 


\section{SONUÇ}

İşletmelerin benimsemiş oldukları finansman politikaları karlılıklarını belirleyen önemli değişkenlerden birisidir. Söz konusu politikaların tercihini belirleyen farklı değişkenler olup, bu değişkenler arasında risk ve faaliyette bulunulan sektör önem arz etmektedir. Risk algısı düşük işletmeler daha çok ihtiyatlı politikalar tercih ederken, risk algısı yüksek olan işletmeler ise atılgan politikalar tercih edebilmektedir. Fakat bu tercihler sonucu ortaya çıkan riskler ise işletmelerin faaliyette bulunduğu sektörlerden bağımsız değildir. $\mathrm{Bu}$ bağlamda üretim sektöründe faaliyette bulunan işletmeler, karlılığı arttırmak amaciyla borçlanmaya ağırlık vererek atılgan finansman politikaları tercih etmeleri durumunda, varlık yapıları içerisindeki duran varlıkların ağırlığı nedeniyle riskleri artmakta, bu durum ise varlık kaynak uyumsuzluğu nedeniyle karlılığı olumsuz etkileyebilmektedir.

Çalışmada BİST'te işlem gören 10 çimento şirketinin 1998-2016 tarihleri arasına ilişkin 3'er aylık verileri kullanılarak, kısa vadeli borçlanma oranları, stok tutma süreleri ve alacakların tahsil süreleri ile aktif karlılıkları arasındaki ilişki incelenmiştir. Analiz sonucunda işletmelerin finansman politikalarında kısa vadeli borçlanmaya ağırlık vermelerinin, aktif karlılıklarını olumsuz etkilediği, bununla birlikte söz konusu etkinin zayıf olduğu sonucuna ulaşılmıştır. $\mathrm{Bu}$ durum söz konusu işletmelerin üretim sektöründe faaliyette bulunmaları nedeniyle, kısa vadeli borçlanmaya ağırlık vermeleri durumunda risklerinin artması ve varlık kaynak yapısı arasındaki vade uyumunun bozulması ile açıklanabilir. Bu nedenle işletmelerin varlık finansmanı için belirlemiş oldukları politika tercihleri noktasında, faaliyette bulundukları sektörleri göz önünde bulundurmaları gerekmektedir. Çalışmada kullanılan bir diğer bağımsız değişken olan stok tutma süresi ile aktif karlılığı arasında negatif yönlü ilişki olduğu sonucuna ulaşılmıştır. Bu durum, işletmelerin daha kısa sürede stoklarını nakite çevirmelerinin satış hacimlerini arttırarak, kaynak ihtiyacı ve maliyetlerinin azalması sonucunda, karlılıklarının artabileceğini ifade etmektedir. Çalışmada kısa vadeli borçlanma oranı, stok tutma süresi ve alacakların tahsil süresinin aktif karlılığını etkilemesi modellenirken en çok olabilirlik yönteminin kullanılmış olması ve çimento şirketlerinin çoğunda bu etkinin aynı yönde çıkması konu ile alakalı literatüre farklı bir katkı sağlamıştır.

\section{KAYNAKLAR}

Akkaya, G. Cenk. (2008), “Sermaye Yapısı, Varlık Verimliliği ve Karlılık: İMKB’de Faaliyet Gösteren Deri-Tekstil Sektörü İşletmeleri Üzerine bir Uygulama”, Erciyes Üniversitesi İktisadi ve İdari bilimler Fakültesi Dergisi, Sayı:30, ss. 1-13.

Albayrak, Ali Sait - Akbulut, Ramazan (2008). "Karlılığı Etkileyen Faktörler: İmkb Sanayi Ve Hizmet Sektörlerinde İşlem Gören İşletmeler Üzerine Bir İnceleme”, ZKÜ Sosyal Bilimler Dergisi, 4(7), ss. 55-83.

Aydın, Nurhan - Başar, Mehmet - Coşkun, Metin (2014), Finansal Yönetim, Detay Yayınc1lık, Ankara.

Bektöre, Sabri - Çömlekçi, Ferruh - Sözbilir, Halim (2015), Mali Tablolar Analizi, Nisan Kitabevi, Ankara.

Ceylan, Ali - Korkmaz, Turhan (2013), İşletmelerde Finansal Yönetim, Ekin Yayınevi, Bursa. 
Chechet, Ishaya Luka - Olayiwola, Abduljeleel Badmus (2014), "Capital Structure and Profitability Of Nigerian Quoted Firms: The Agency Cost Theory Perspective”, American International Journal Of Social Science 3(1), ss. 139-158.

Çabuk, Adem, - Lazol, İbrahim (2013), Mali Tablolar Analizi, Ekin Yayınevi, Bursa.

Çokluk, Ömay (2010), “Kuram ve Uygulamada Eğitim Bilimleri”, Educational Sciences: Thory \& Practice, 10(3), Yaz / Summer 2010, ss. 1357-1407.

Çokluk, Ömay - Şekercioğlu, Güçlü - Büyüköztük, Şener (2012), Sosyal Bilimler İçin Çok Değişkenli İstatistik SPSS ve LİSREL Uygulamaları, 2.Baskı, Pegem Akademi, Ankara.

Doğan, Mesut (2013), "Sigorta Firmalarının Sermaye Yapısı ile Karlılık Arasındaki İlişki: Türk Sermaye Piyasası Üzerine Bir İnceleme", Muhasebe ve Finansman Dergisi, Say1:57, ss. 121-136.

Hussain, Tajamul (2015), "Does Capital Structure Effects Profitability of The Firms (Evidence from Firms Listed at KSE 100 Index)”, Research Journal of Finance and Accounting, 6(5), ss. 116-123.

İskenderoğlu, Ömer - Karadeniz, Erdinç - Atioğlu, Eyüp (2012), “Türk Bankacılık Sektöründe Büyüme, Büyüklük ve Sermaye Yapısı Kararlarının Karlılığa Etkisinin Analizi”, Eskişehir Osmangazi Üniversitesi İİBF Dergisi, 7(1), ss. 291-311.

İslamoğlu, Hamdi - Alnıaçık, Ümit (2014), Sosyal Bilimlerde Araştırma Yöntemleri, Beta Yayınevi. İstanbul.

Kalaycı, Şeref (2005), SPSS Uygulamalı Çok Değişkenli İstatistik Teknikleri, 1.Baskı, Asil Yayın Dağıtım, Ankara.

Karadeniz, Erdinç - İskenderoğlu, Ömer (2011), “İstanbul Menkul Kıymetler Borsası'nda İşlem Gören Turizm İşletmelerinin Aktif Kârlılığını Etkileyen Değişkenlerin Analizi”, Anatolia:Turizm Araştırmaları Dergisi, 22(1), ss. 65-75.

Karadeniz, Erdinç - Kaplan, Fatih - Günay, Fatih (2016), "Sermaye Yapısı Kararlarının Kârlılığa Etkisi: Borsa İstanbul Turizm Şirketlerinde Bir Araştırma”, Seyahat ve Otel İşletmeciliği Dergisi, 13(3), ss. 38-55.

Makori, Daniel Mogaka - Jagongo, Ambrose (2013), "Working Capital Management And Firm Profitability: Empirical Evidence From Manufacturing And Construction Firms Listed On Nairobi Securities Exchange, Kenya”, International Journal of Accounting and Taxation, 1(1), ss. 1-14.

Mohamad, Nor Edi Azhar Binti - Saad, Noriza Binti Mohd (2010), "Working Capital Management: The Effect Of Market Valuation And Profitability In Malaysia”, International Journal of Business and Management, 5(11), ss. 140-147.

Okka, Osman (2011), İşletme Finansmanı, Nobel Yayıncılık, Ankara. 
Raheman, Abdul - Nasr, Mohamed (2007), “Working Capital Management And ProfitabilityCase Of Pakistani Firms”, International Review Of Business Research Papers, 3(1), ss. 279-300.

Sakarya, Şakir (2008), "Nakit Yönetiminde Nakit Dönüş Süresi Analizinin Kullanılması: İMKB'deki KOBİ'ler Üzerine Ampirik Bir Çalışma”, Süleyman Demirel Üniversitesi İktisadi ve İdari Bilimler Fakültesi Dergisi, Cilt:13, Sayı:2, ss.227-248.

Salawu, Rafiu Oyesola (2009), “The Effect Of Capital Structure On Profitability: An Empirical Analysis Of Listed Firms In Nigeria”, The International Journal Of Business And Finance Research, 3(2), ss. 121-129.

Topal, Yusuf (2006), “IMKB’ye Kayıtlı İşletmelerin Sermaye Yapıları ve Finansal Kaldıraç Oranlarının Karlılıklarına Etkisi", Erciyes Üniversitesi İktisadi ve İdari Bilimler Fakültesi Dergisi, Sayı:27, ss. 45-70.

Toroslu, M. Vefa - Durmuş, Cem Niyazi (2015), Finansal Tablolar Analizi, Seçkin Yayınevi, Ankara.

Zubairi, H. Jamal (2010), “Impact Of Working Capital Management And Capital Structure On Profitability Of Automobile Firms In Pakistan”, https://papers.ssrn.com/sol3/papers.cfm?abstract_id=1663354. (Erişim Tarihi: 20.07.2017). 
